\title{
Subclinical hypothyroidism would not lead to female sexual dysfunction in Chinese women
}

\author{
Han Luo', Wanjun Zhao ${ }^{1}$, Hongliu Yang ${ }^{2,3}$, Qianqian Han²,3 ${ }^{2,3}$ Zeng ${ }^{4}$, Huairong Tang ${ }^{4 *}$ and Jingqiang Zhu ${ }^{1 *}$ (D)
}

\begin{abstract}
Background: There is dearth of research about female sexual dysfunction (FSD), especially in China, because of conservative beliefs. Previous studies indicated the relationship between subclinical hypothyroidism and anxiety and depression. However, there is dearth of research regarding the relationship between subclinical hypothyroidism and FSD in Chinses women.

Method: A hospital-based research was conducted. Female sexual function was measured by CVFSFI which includes 19 items. Participants were identified as FSD if CVFSFI $\leq 23.45$. Logistics analysis was used to determine risk factor of FSD. All of them finished CVFSFI, Beck Depression Inventory (BDI) self-reporting questionnaires and had thyroid hormone tests. Based on presence and absence of subclinical hypothyroidism, participants were divided into two groups. Risk factors of FSD were identified.

Result: One thousand one hundred nineteen participants with CVFSFI score $25.8 \pm 3.9$ were enrolled in final analysis. Incidence of subclinical hypothyroidism and FSD in Chinese women was 15.0\% and 26.5\% respectively.

There were no significant difference between subclinical hypothyroidism and control group in FSFI score and prevalence of FSD. Age, Depression (medium risk) was identified as risk factors for nearly all types of FSD, and Income (ranges from 40,000 to 100,000 RMB/year) as protective factor. Subclinical hypothyroidism had no significant relationship with FSD.
\end{abstract}

Conclusion: Subclinical hypothyroidism is not the risk factor for FSD in urban women of China.

Keywords: Chinese version of the female sexual function index, Beck depression inventory, Female sexual dysfunction, Subclinical hypothyroidism, Thyroid

\section{Background}

Since early 1950s, researchers began to investigate sexual dysfunction. And absolutely most of studies focused on erectile dysfunction, premature ejaculation et al. male sexual issue $[1,2]$. However, with increasing socioeconomic status in current society, female health is not an ignorable concern nowadays [3, 4]. Until recent decade, researchers began to shift attention to this topic,

\footnotetext{
*Correspondence: HuairongTang@163.com; zjq-wkys@163.com

${ }^{4}$ Health Promotion Center, West China Hospital, Sichuan University, West China Hospital, Guoxue Alley 37\#, Chengdu, Sichuan, People's Republic of ChinaPostal code: 610041

'Department of Thyroid \& Parathyroid surgery, West China Hospital, Sichuan University, West China Hospital, Guoxue Alley 37\#, Chengdu, Sichuan,

People's Republic of ChinaPostal code: 610041

Full list of author information is available at the end of the article
}

and the first female "Viagra"-Flibanserin was approved by American FDA in 2016, but there was a dearth of literature about Chinese female sexual dysfunction (FSD).

Lack of, or significantly decreased sexual interest or arousal manifested by at least three of the following characteristics should be identified as FSD: (i) absent or decreased interest in sexual activity; (ii) absent or decreased sexual or erotic thoughts or fantasies; (iii) no or decreased initiation of sexual activity and typically unreceptive to a partner's attempts to initiate; (iv) absent or decreased sexual excitement or pleasure during sexual activity in almost all or all (approximately $75 \%-100 \%$ ) sexual encounters (in identified situational contexts or, if generalized, in all contexts); (v) absent or decreased sexual interest or arousal in response to any internal or 
external sexual or erotic cues (eg, written, verbal, or visual); or (vi) absent or decreased genital or non-genital sensations during sexual activity in almost all or all (approximately 75\%-100\%) sexual encounters (in identified situational contexts or, if generalized, in all contexts) [5]. According to different studies, prevalence of FSD varies from $25 \%$, by Kammerer-Doak, to $63 \%$, by Rogers [6]. So it is a common entity besetting women in worldwide. However, the incidence is uncertain in China, especially after the optimal cutoff value was determined by Ma and his team [7] in 2014 basing on the Chinese Han ethnic, the biggest population in China.

FSD is a multifactorial problem $[8,9]$. Previous literatures reported psychological factors (irritation, depression and anxiety et al.) and socioeconomic factors (income, education background and living condition) is associated with FSD [10-12]. Meanwhile, endocrinal messengers e.g. prolactin [13], gonadal hormone [14, 15] usually has impact on female sexual function.

Additionally, thyroid disorder-hypothyroidism is believed to associate with FSD $[10,16]$. But relationship between subclinical hypothyroidism $(\mathrm{ScHt})$ and FSD is still not clear because of paucity of evidence. Previously, Ergenekon observed that a significantly more women with ScHt of TSH values $>10 \mathrm{mU} / \mathrm{L}$ had sexual dysfunction [16]. By contrast, Lee et al. demonstrated that ScHt is not a risk factor for FSD in Korean middle-aged women [17].

Due to the controversies in the topic, a preliminary screening study exploring risk factor for FSD with optimal diagnostic value for Chinese was conducted firstly in China.

\section{Methods}

This hospital-based survey was conducted in Health Promotion Center of West China Hospital between June and December of 2015. The health promotion center provided routine check-ups for each member. As described in previous study [18], all of approached women who meet criteria was included in the final analysis.

The diagnosis of Hashimoto thyroiditis referred to Caturegli P's review [19]. Included subjects were divided into two groups-ScHT and control group, according to thyroid hormone tests. The reference of thyroid hormone and antibody was the same in previous study [18].

Validated by Sun et al. in 2011 [20], Chinese Version of the FSFI (CVFSFI) was adopted to evaluate female sexual function. According to research of $\mathrm{Ma}$ et al. in 2014 [7], female sexual dysfunction was defined as a CVFSFI score $\leq 23.45$. And 2.7, 3.15, 4.05, 3.8, 3.6 and 3.8 was chosen as optimal cutoff values for low desire/ arousal/lubrication/orgasm/satisfaction/sexual pain in the research. In the study, psychological status was evaluated by second version of Beck Depression Inventory (BDI-II), as described in previous study [18].
SPSS version 21 (SPSS Inc., Chicago, IL) was used in the data analysis. Variables were presented as the mean \pm standard deviation or median (interquartile range) and compared by t-test or U-test. Chi-square test was used to compare frequency for categorical variables. Risk factor was identified by logistic regression. $P$ value less than 0.05 indicates significance.

\section{Results}

During the enrollment period, a total of 1314 women approved to participate in the study. And 1265 women completed the CVFSFI questionnaires in high quality. Then 146 participants were excluded since overt hyperor hypothyroidism. Finally, 1119 participants came into final analysis, including $168 \mathrm{ScHt}$ participants (15.0\%). The baseline were shown in Table 1.

Significantly more participants with Hashimoto Thyroiditis (HT) in ScHT group than control, $14.28 \%$ $(24 / 168)$ vs $5.25 \%(50 / 951)$ respectively, $(p<0.001)$. Table 1. Besides, significantly more participants were perimenopaused and married in ScHT group, compared with control group, $p=0.047,0.016$, respectively.

With respect to FSFI score, a total of 297 participants $(26.5 \%)$ were at risk for FSD (FSFI score $\leq 23.45$ ), including 36 in ScHT group (21.4\%) and 261 in control group $(27.4 \%)$, no significant difference $(p=0.108)$. Incidence of low desire/ low arousal/ low lubrication/ low orgasm/ low satisfaction and sexual pain in ScHT group was $14.3 \%, 17.9 \%, 21.4 \%, 21.4 \%, 23.2 \%$ and $23.2 \%$ respectively. Comparatively, it was $17.7 \%, 16.0 \%, 19.6 \%, 22.1 \%$, $22.7 \%$ and $23.7 \%$ respectively in control group. Therefore, two groups had no significant difference in FSD and subtype of FSD, as shown in Table 2.

Adjusted by cofounding variables, it was clear to find that Age was a common risk factor for FSD. Adjusted odd ratio (OR) was 1.086 (1.021, 1.155), 1.087 (1.023, $1.155), 1.118(1.050,1.191)$ and $1.059(1.001,1.120)$ in Desire, Arousal, Lubrication and FSD, respectively, Table 3. Likely, Depression was common risk factor for all types of FSD. And it is interesting to see that higher Income (40,000-100,000 RMB/year) was a protective variable for nearly all types of FSD. However, it would impair female sexual ability when income $>100,000$ $\mathrm{RMB} /$ year. BMI was identified as risk factor for Low Desire $(1.281$ [1.121, 1.463], $p<0.001)$. Besides, we failed to found a determined relationship between ScHT with any type of FSD. Table 3.

\section{Discussion}

To our limited knowledge, it is the first study to explore the relationship between thyroid hormone and female sexual dysfunction (FSD) in China. Though Lee et al. firstly has proved subclinical hypothyroidism (ScHT) is not risk factor for FSD [17], they failed to set the 
Table 1 Basic characters comparison between subclinical hypothyroidism and control group

\begin{tabular}{|c|c|c|c|}
\hline & $\mathrm{ScHT}(N=168)$ & Control $(N=951)$ & $P$ value \\
\hline Age & $39.2 \pm 7.6$ & $38.5 \pm 7.7$ & 0.548 \\
\hline Height & $158.2 \pm 4.8$ & $158.9 \pm 5.2$ & 0.416 \\
\hline Weight & $55.3 \pm 8.1$ & $54.7 \pm 6.6$ & 0.561 \\
\hline BMl & $22.1 \pm 3.0$ & $21.7 \pm 2.4$ & 0.304 \\
\hline fT3 & $5.0 \pm 0.6$ & $5.0 \pm 0.7$ & 0.999 \\
\hline fT4 & $16.4 \pm 2.1$ & $17.1 \pm 2.2$ & 0.045 \\
\hline Systolic pressure & $109.6 \pm 15.7$ & $108.6 \pm 13.1$ & 0.631 \\
\hline Diastolic pressure & $69.9 \pm 10.2$ & $69.0 \pm 8.9$ & 0.500 \\
\hline TSH & $5.4(4.7,6.5)$ & $2.3(1.7,2.9)$ & $<0.001$ \\
\hline TPOab & $9.0(5.2,41.5)$ & $7.9(5.2,13.1)$ & 0.124 \\
\hline Tgab & $19.6(14.9,149.9)$ & $17.9(13.8,23.5)$ & 0.022 \\
\hline Hypertension $(\mathrm{Y} / \mathrm{N})$ & $12 / 156(7.14 \%)$ & $47 / 904$ (4.94\%) & 0.259 \\
\hline Diabetes $(\mathrm{Y} / \mathrm{N})$ & 6/162 (3.57\%) & $32 / 919(3.36 \%)$ & 0.819 \\
\hline Hashimoto Thyroiditis (Y/N) & $24 / 144(14.28 \%)$ & $50 / 901(5.25 \%)$ & $<0.001$ \\
\hline Perimenopause (Y/N) & 24/144 (14.28\%) & 201/750 (21.14\%) & 0.047 \\
\hline Menopause (Y/N) & $6 / 162(3.57 \%)$ & 28/923(2.94\%) & 0.627 \\
\hline Smoking & & & 0.603 \\
\hline Never & $168(100 \%)$ & 944 (99.26\%) & \\
\hline Current & 0 & 7 & \\
\hline Alcohol consumption & & & 0.446 \\
\hline Never & 162 (96.43\%) & 900 (94.64\%) & \\
\hline Rarely & $6(3.57 \%)$ & $51(5.36 \%)$ & \\
\hline Marital status & & & 0.016 \\
\hline Married & $168(100 \%)$ & 921 (96.85\%) & \\
\hline Unmarried & 0 & $30(3.15 \%)$ & \\
\hline Education status & & & 0.401 \\
\hline$\leq$ Middle School & $81(48.21 \%)$ & $423(44.48 \%)$ & \\
\hline$\geq$ University & 87 (51.79\%) & $528(55.52 \%)$ & \\
\hline Income (RMB/year) & & & 0.607 \\
\hline$\leq 40,000$ & $30(17.86 \%)$ & 207 (21.77\%) & \\
\hline $40,000-100,000$ & $132(78.57 \%)$ & $693(72.87 \%)$ & \\
\hline$\geq 100,000$ & $6(3.57 \%)$ & $51(5.36 \%)$ & \\
\hline Physical activity & & & 0.552 \\
\hline No & $36(21.43 \%)$ & $174(18.30 \%)$ & \\
\hline Rarely & 45 (26.79\%) & 276 (29.02\%) & \\
\hline Frequently & 87 (51.79\%) & $501(52.68 \%)$ & \\
\hline Depression status & & & 0.727 \\
\hline No & $132(78.57 \%)$ & 774 (81.39\%) & \\
\hline Light & 33 (19.64\%) & 147 (15.46\%) & \\
\hline Medium & $3(1.79 \%)$ & 30 (3.15\%) & \\
\hline Severe & 0 & 0 & \\
\hline Parity ${ }^{a}$ & $1(1,1)$ & $1(1,1)$ & 0.162 \\
\hline
\end{tabular}

ScHT subclinical hypothyroidism, fT3 free triiodothyronine, $f T 4$ free thyroxine, $B M I$ body mass index $P<0.05$ shows significant difference

${ }^{\text {a }}$ Compared by U-test 
Table 2 CVFSFI score and FSD comparison between subclinical hypothyroidism and control group

\begin{tabular}{llll}
\hline & ScHT $(N=168)$ & Control $(N=951)$ & $P$ value \\
\hline Total CVFSFI Score & $25.8 \pm 3.9$ & $25.7 \pm 3.9$ & 0.869 \\
Desire & $3.5 \pm 0.84$ & $3.4 \pm 0.8$ & 0.466 \\
Arousal & $3.9 \pm 1.0$ & $3.9 \pm 0.9$ & 0.844 \\
Lubrication & $4.9 \pm 0.9$ & $4.9 \pm 0.9$ & 0.919 \\
Orgasm & $4.3 \pm 0.9$ & $4.4 \pm 0.8$ & 0.628 \\
Satisfaction & $4.6 \pm 0.9$ & $4.6 \pm 0.8$ & 0.780 \\
Pain & $4.6 \pm 1.0$ & $4.5 \pm 0.9$ & 0.622 \\
FSD (CVFSFI total score $\leq 23.45)$ & $36(21.4 \%)$ & $261(27.4 \%)$ & 0.108 \\
Low Desire $(\leq 2.7)$ & $24(14.3 \%)$ & $168(17.7 \%)$ & 0.319 \\
Low Arousal $(\leq 3.15)$ & $30(17.9 \%)$ & $152(16.0 \%)$ & 0.571 \\
Low Lubrication $(\leq 4.05)$ & $36(21.4 \%)$ & $186(19.6 \%)$ & 0.600 \\
Low Orgasm $(\leq 3.8)$ & $36(21.4 \%)$ & $210(22.1 \%)$ & 0.920 \\
Low Satisfaction $(\leq 3.6)$ & $39(23.2 \%)$ & $216(22.7 \%)$ & 0.921 \\
Sexual Pain $(\leq 3.8)$ & $39(23.2 \%)$ & $225(23.7 \%)$ & 1.000 \\
\hline
\end{tabular}

ScHT subclinical hypothyroidism, CVFSFI Chinese Version of Female Sexual Function Index, FSD female sexual dysfunction

$P<0.05$ shows significant difference

relationship between thyroid hormone and FSD. At the same time, our study also is the first screening research based on the Ma et al.'s optimal cutoff value after $2014[7,20]$.

In our current study, it is interesting to know that the incidence of subclinical hypothyroidism and female sexual dysfunction is $15.0 \%$ and $26.5 \%$ respectively. As we know, the prevalence of subclinical hypothyroidism is higher than previous reports [21, 22], which is mainly resulted from iodine deficiency. Sichuan province locates at western inside mountainous land of China, and element iodine is relative deficient, so government forces to sell iodized salt for 16 years. Incidence of iodine deficiency-related thyroid disease decreases much [23]. Meanwhile, there was no significant difference between ScHT group and control group in Female Sexual Function Index (FSFI) score $(25.8 \pm 3.9$ vs $25.7 \pm 3.9)$. ScHT was not a risk factor for FSD even though after adjustment, which confirmed the Lee's findings [17].

Our study suggested that less than one third-26.5\% of women was beset by FSD. Reportedly, Laumann et al. found that $43 \%$ of American women was at risk for FSD [24]. $52 \%$ of interviewed women had at least one type of FSD in an Iranian population-based study [25]. The number in Egypt is $52.8 \%$ according to Ibrahim et al. report [26]. In all, the difference was mainly resulted from different ethnics, cutoff value and conservative culture background-Chinese women are reluctant to talk it with physicians. On the other hand, it coincided with researches in Iran, Turkey, Medellin and Malaysia, which reported the prevalence was $31.5 \%, 26.1 \%, 30 \%$, $29.6 \%$ respectively [27-30]. Though previous research conducted by Sefa Resim et al. found that education level of male and female was found to be significantly related to FSD [31], we found higher education ( $\geq$ University) was not protective factor for FSD. This may be resulted from different classifier-in Sefa Resim's report, participants was divided into illiterate, schooling $<8$ years and $>8$ years.

Subclinical hypothyroidism, affecting $10 \%$ of population, is more frequently detected in women than men, and advanced age [21, 32]. Due to the influence of thyroid hormone on lipid metabolism, subclinical hypothyroidism is proved to be risk factor for heart failure, coronary heart disease and dyslipidemia [33-37]. But the research about the relationship between subclinical hypothyroidism and FSD is rare. In previous study, Atis G et al. reported that a significant percent of women with clinic hypothyroidism and subclinical hypothyroidism with TSH values $>10 \mathrm{mIU} /$ $\mathrm{L}$ had sexual dysfunction. Subclinical hypothyroidism, however, with $\mathrm{TSH}$ values $<10 \mathrm{mIU} / \mathrm{L}$ did show this trend [16]. It shared the same view with our study, because only 6 participant with TSH more than $10 \mathrm{mIU} / \mathrm{L}$ were enrolled in our study. Thus TSH in absolutely most of participants was lower than $10 \mathrm{mIU} / \mathrm{L}$ in the present study. And it is found that ScHT is not risk factor for any type of FSD. Therefore, the result, in fact, kept consistent with Atis G's.

Several limitations are inevitable in our study. First of all, it is limited by the location. West China Hospital locates southwestern part of China. People intend to be more conservative than in Beijing or costal region, especially to sexual life or experience, because of comparatively less developed economy. Reportedly, Sun et al. found prevalence of FSD was $52 \%$ in Beijing, but they 


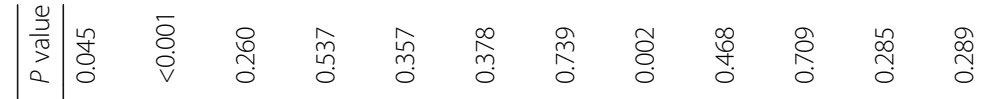

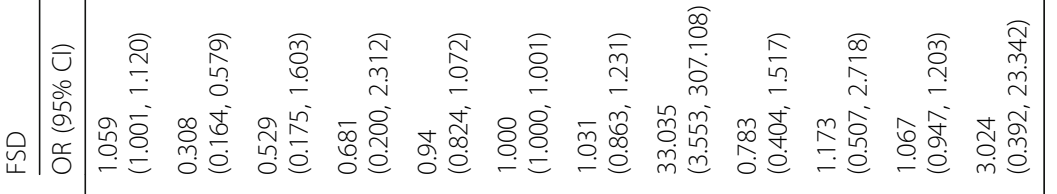
芳豙

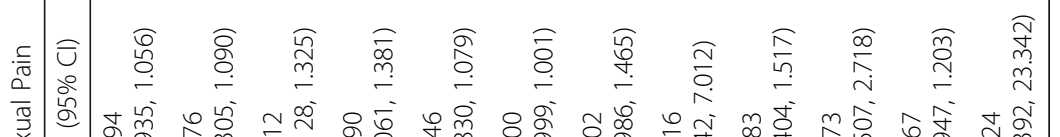

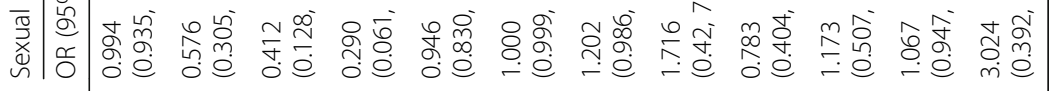

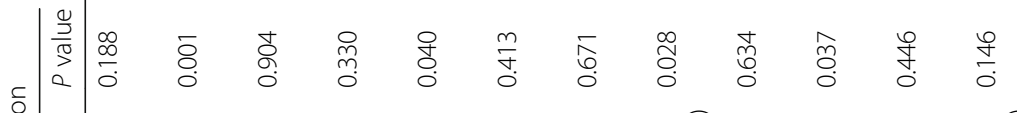

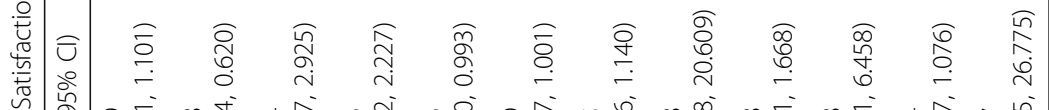

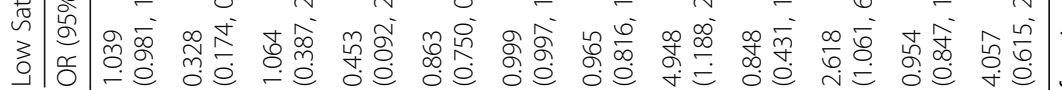
J)

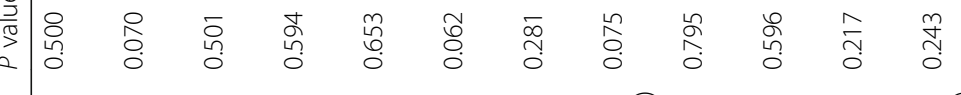

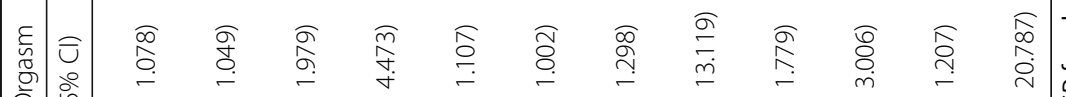

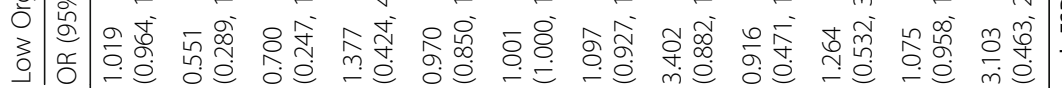

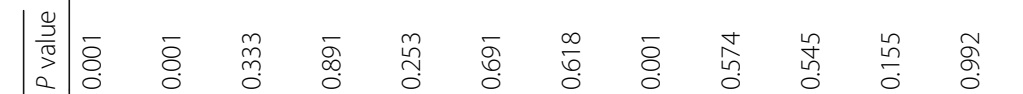

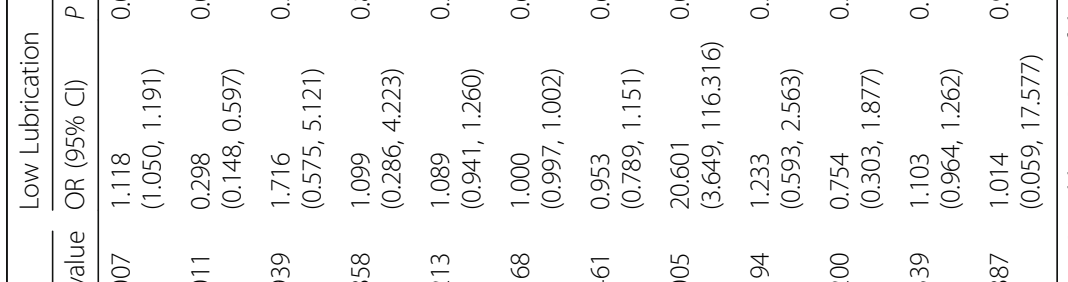
党

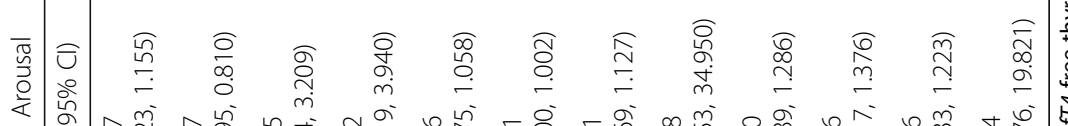

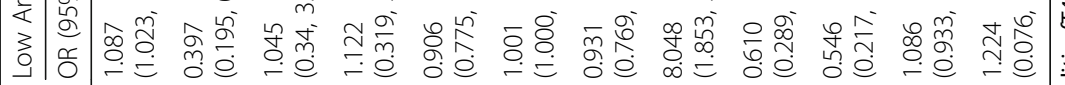

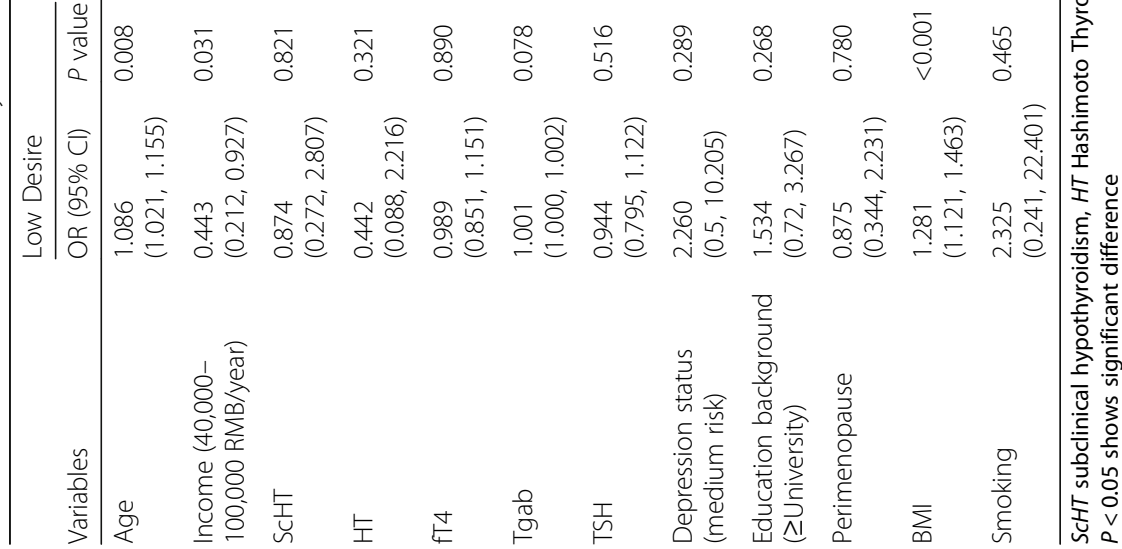


used DSM-IV-TR, not FSFI as screening tool. And the result in our study hardly has general representativeness for a whole population due to uneven development of economy and culture. Therefore, we look forward more researchers could focus on this topic. Secondly, short of diversity is inevitable, because the absolutely most of participants come from urban region. The result may be a little different when adopted in urban and suburban area. Therefore, a multicenter screening study is needed. Thirdly, due to the limitation of health examination programs, sex hormone, like testosterone, estradiol, luteinizing hormone et al., cannot be collected. An extensive study involving sex hormone is conducting in department.

\section{Conclusions}

In conclusion, the prevalence of female sexual dysfunction and subclinical hypothyroidism in China, southwestern part of China exactly, was $26.5 \%$ and $15.0 \%$, respectively. And subclinical hypothyroidism is not risk factor for any type of FSD.

\section{Abbreviations}

BDI: Beck Depression Inventory; CVFSFI: Chinese version of the female sexual function index; FSD: Female sexual dysfunction.

\section{Acknowledgements}

Thank every staff in health promotion center for kind help, especially gynecological physician Dr. He. Gleber-Netto FO (Head \& Neck Surgery, MD Anderson Cancer Center, University of Texas) for language revision.

\section{Funding}

Not applicable.

\section{Availability of data and materials}

Data sharing not applicable to this article as no datasets were generated or analyzed during the current study. Confidential participants' information will not be shared. Any question about summarized data, please contact correspondence author.

\section{Authors' contributions \\ Concept design: JQZ, HRT. Acquisition of data: WJZ, QQH, LZ. Interpretation of data: JQZ. Data analysis: HLY. Manuscript draft and revision: HL. All of authors agree the final version to be published, and take responsibility for the accuracy of data in the study.}

\section{Ethics approval and consent to participate}

This study was approved by ethics committee board of West China Hospital, Sichuan University. All study participants provided a written informed consent to agree the clinical data to be used in clinical research and publication.

\section{Consent for publication}

Not applicable.

\section{Competing interests}

The authors declare that they have no competing interests.

\section{Publisher's Note}

Springer Nature remains neutral with regard to jurisdictional claims in published maps and institutional affiliations.

\section{Author details}

'Department of Thyroid \& Parathyroid surgery, West China Hospital, Sichuan University, West China Hospital, Guoxue Alley 37\#, Chengdu, Sichuan, People's Republic of ChinaPostal code: 610041. ${ }^{2}$ Department of Nephrology, West China Hospital, Sichuan University, Sichuan, Chengdu, People's Republic of China. ${ }^{3}$ Biostatistics Center, West China Hospital, Sichuan University, Sichuan, Chengdu, People's Republic of China. ${ }^{4}$ Health Promotion Center, West China Hospital, Sichuan University, West China Hospital, Guoxue Alley 37\#, Chengdu, Sichuan, People's Republic of ChinaPostal code: 610041.

Received: 17 September 2016 Accepted: 3 November 2017 Published online: 25 January 2018

\section{References}

1. ACOG Practice Bulletin No. 119. Female sexual dysfunction. Obstet Gynecol. 117:996-1007.

2. Corona G, FC W, Forti G, Lee DM, O'Connor DB, et al. Thyroid hormones and male sexual function. Int J Androl. 2012;35:668-79.

3. Amidu N, Owiredu WK, Woode E, Addai-Mensah O, Quaye L, et al. Incidence of sexual dysfunction: a prospective survey in Ghanaian females. Reprod Biol Endocrinol. 2010;8:106

4. Laumann EO, Nicolosi A, Glasser DB, Paik A, Gingell C, et al. Sexual problems among women and men aged 40-80 y: prevalence and correlates identified in the global study of sexual attitudes and behaviors. Int J Impot Res. 2005; 17:39-57.

5. McCabe MP, Sharlip ID, Atalla E, Balon R, Fisher AD, et al. Definitions of sexual dysfunctions in women and men: a consensus statement from the fourth international consultation on sexual medicine 2015. J Sex Med. 2016;13:135-43.

6. Clayton AH, Hamilton DV (2009) Female sexual dysfunction. Obstet Gynecol Clin N Am 36: 861-876, xi.

7. Ma J, Pan L, Lei Y, Zhang A, Kan Y. Prevalence of female sexual dysfunction in urban chinese women based on cutoff scores of the Chinese version of the female sexual function index: a preliminary study. J Sex Med. 2014:11:909-19.

8. Salonia A, Munarriz RM, Naspro R, Nappi RE, Briganti A, et al. Women's sexual dysfunction: a pathophysiological review. BJU Int. 2004;93:1156-64.

9. Cayan S, Akbay E, Bozlu M, Canpolat B, Acar D, et al. The prevalence of female sexual dysfunction and potential risk factors that may impair sexual function in Turkish women. Urol Int. 2004;72:52-7.

10. Bhasin S, Enzlin P, Coviello A, Basson R. Sexual dysfunction in men and women with endocrine disorders. Lancet. 2007;369:597-611.

11. Balercia G, Boscaro M, Lombardo F, Carosa E, Lenzi A, et al. Sexual symptoms in endocrine diseases: psychosomatic perspectives. Psychother Psychosom. 2007;76:134-40.

12. Pasquali D, Maiorino MI, Renzullo A, Bellastella G, Accardo G, et al. Female sexual dysfunction in women with thyroid disorders. J Endocrinol Investig. 2013;36:729-33.

13. Prabhakar VK, Davis JR. Hyperprolactinaemia. Best Pract Res Clin Obstet Gynaecol. 2008:22:341-53.

14. Brenta G, Schnitman M, Gurfinkiel M, Damilano S, Pierini A, et al. Variations of sex hormone-binding globulin in thyroid dysfunction. Thyroid. 1999;9:273-7.

15. Traish AM, Kim N, Min K, Munarriz R, Goldstein I. Role of androgens in female genital sexual arousal: receptor expression, structure, and function. Fertil Steril. 2002:77(Suppl 4):S11-8.

16. Atis $G$, Dalkilinc A, Altuntas $Y$, Atis A, Caskurlu T, et al. Sexual dysfunction in women with clinical hypothyroidism and subclinical hypothyroidism. J Sex Med. 2010;7:2583-90.

17. Hong H, Lee HJ, Kim SM, Jeon MJ, Shin DW, et al. Subclinical hypothyroidism is not a risk factor for female sexual dysfunction in Korean middle-aged women. Thyroid. 2015;25:784-8.

18. Luo $H$, Yang $H$, Zhao W, Han Q, Zeng $L$, et al. Elevated free triiodothyronine may lead to female sexual dysfunction in Chinese urban women: a hospital-based survey. Sci Rep. 2017;7:1216.

19. Caturegli P, De Remigis A, Rose NR. Hashimoto thyroiditis: clinical and diagnostic criteria. Autoimmun Rev. 2014;13:391-7.

20. Sun X, Li C, Jin L, Fan Y, Wang D. Development and validation of Chinese version of female sexual function index in a Chinese population-a pilot study. J Sex Med. 2011;8:1101-11. 
21. Canaris GJ, Manowitz NR, Mayor G, Ridgway EC. The Colorado thyroid disease prevalence study. Arch Intern Med. 2000;160:526-34.

22. Kanaya AM, Harris F, Volpato S, Perez-Stable EJ, Harris T, et al. Association between thyroid dysfunction and total cholesterol level in an older biracial population: the health, aging and body composition study. Arch Intern Med. 2002;162:773-9.

23. Shan Z, Chen L, Lian X, Liu C, Shi B, et al. lodine status and prevalence of thyroid disorders after introduction of mandatory universal salt iodization for 16 years in China: a cross-sectional study in 10 cities. Thyroid. 2016;26:1125-30.

24. Laumann EO, Paik A, Rosen RC. Sexual dysfunction in the United States: prevalence and predictors. JAMA. 1999;281:537-44.

25. Goshtasebi A, Vahdaninia M, Rahimi Foroshani A. Prevalence and potentia risk factors of female sexual difficulties: an urban Iranian population-based study. J Sex Med. 2009:6:2988-96.

26. Ibrahim ZM, Ahmed MR, Sayed Ahmed WA. Prevalence and risk factors for female sexual dysfunction among Egyptian women. Arch Gynecol Obstet. 2013;287:1173-80

27. Echeverry MC, Arango A, Castro B, Raigosa G. Study of the prevalence of female sexual dysfunction in sexually active women 18 to 40 years of age in Medellin, Colombia. J Sex Med. 2010;7:2663-9.

28. Sidi H, Puteh SE, Abdullah N, Midin M. The prevalence of sexual dysfunction and potential risk factors that may impair sexual function in Malaysian women. J Sex Med. 2007:4:311-21.

29. Safarinejad MR. Female sexual dysfunction in a population-based study in Iran: prevalence and associated risk factors. Int J Impot Res. 2006;18:382-95.

30. Oniz A, Keskinoglu P, Bezircioglu I. The prevalence and causes of sexual problems among premenopausal Turkish women. J Sex Med. 2007:4:1575-81.

31. Kucukdurmaz F, Efe E, Malkoc O, Kolus E, Amasyali AS, et al. Prevalence and correlates of female sexual dysfunction among Turkish pregnant women. Turk J Urol. 2016;42:178-83.

32. Hollowell JG, Staehling NW, Flanders WD, Hannon WH, Gunter EW, et al. Serum TSH, T(4), and thyroid antibodies in the United States population (1988 to 1994): National Health and nutrition examination survey (NHANES III). J Clin Endocrinol Metab. 2002:87:489-99.

33. Rodondi N, den Elzen WP, Bauer DC, Cappola AR, Razvi S, et al. Subclinical hypothyroidism and the risk of coronary heart disease and mortality. JAMA. 2010;304:1365-74

34. Gencer B, Collet TH, Virgini V, Bauer DC, Gussekloo J, et al. Subclinical thyroid dysfunction and the risk of heart failure events: an individual participant data analysis from 6 prospective cohorts. Circulation. 2012:126:1040-9.

35. Hyland KA, Arnold AM, Lee JS, Cappola AR. Persistent subclinical hypothyroidism and cardiovascular risk in the elderly: the cardiovascular health study. J Clin Endocrinol Metab. 2013;98:533-40.

36. Rodondi N, Bauer DC, Cappola AR, Cornuz J, Robbins J, et al. Subclinical thyroid dysfunction, cardiac function, and the risk of heart failure. The cardiovascular health study. J Am Coll Cardiol. 2008;52:1152-9.

37. Meier C, Staub JJ, Roth CB, Guglielmetti M, Kunz M, et al. TSH-controlled L-thyroxine therapy reduces cholesterol levels and clinical symptoms in subclinical hypothyroidism: a double blind, placebo-controlled trial (Basel thyroid study). J Clin Endocrinol Metab. 2001;86:4860-6.

\section{Submit your next manuscript to BioMed Central and we will help you at every step:}

- We accept pre-submission inquiries

- Our selector tool helps you to find the most relevant journal

- We provide round the clock customer support

- Convenient online submission

- Thorough peer review

- Inclusion in PubMed and all major indexing services

- Maximum visibility for your research

Submit your manuscript at www.biomedcentral.com/submit

) Biomed Central 